\title{
Modeling and forecasting of GRP based on R. Solow model
}

\author{
Kokotkina T.N., Sadovin N.S., Tsaregorodtsev E.I., Barkalova T.G. \\ Mari State University, MarSU \\ Yoshkar-Ola, Russia \\ tanyakokotkina@gmail.com
}

\begin{abstract}
The article is devoted to the question of using $\mathbf{R}$. Solow dynamic macroeconomic model of economic growth for modeling and forecasting the dynamics of the gross regional product by the example of the Volga Federal District regions. The models were built in current and comparable prices with and without the lag when entering funds. The multiplicative production functions with and without the scientific and technical progress were taken as a production function. For the model implementation, the following macroeconomic indicators were selected: gross regional product, cost of fixed production assets, population, the number of labor resources employed in the economy and the number of economically active population. The article shows the results of numerical experiments on the implementation of $\mathbf{R}$. Solow models, calculation of parameters that characterise scientific and technical progress, including the Solow residual, and the results of forecasting the gross regional product for the Volga Federal District. The corresponding software "EGRMod" was developed to work under Windows OS in the MS Access environment or under the control of the Access Runtime library. To accumulate data, an external Access database is used. Numerical calculations are performed in SQL using VBA. The research is supported by Russian Science Foundation project \#16-18-10017 «Complex of programs for forecasting economic development of the region».
\end{abstract}

Keywords - Gross regional product, economic growth, modeling, forecasting, production function, R. Solow model, Solow residual

\section{INTRODUCTION}

The dynamic one-factor model of economic growth by the American economist Robert Merton Solow is the starting point of almost any research in the field of economic growth. Using this model, one can identify the causes of temporary and permanent sustainable economic growth, analyze the intercountry and interregional differences [4] in the level of social and economic development. R. Solow clearly showed that in neo-Keynesian models, the instability of dynamic equilibrium was primarily caused by the noninterchangeability of resources, factors of production. Therefore, in his model of economic growth, instead of the production function of $\mathrm{V}$. Leontyev, he used the modified Cobb-Douglas production function [1], in which such factors of production as labor and capital are substitutes. The following factors can be considered as key reasons for applying R.Solow model: the diminishing marginal productivity of capital, the constant return on scale, the constant rate of retirement and the absence of investment lags. The interchangeability of production factors in this model can be explained not only by technological conditions, but also by the neoclassical premise of perfect competition in the markets for production resources. Technical progress in the Solow model is set exogenously, and the model works with the effects associated with the distribution of income between consumption and investment [10].

With regard to the scientific and technical factor, R. Solow macroeconomic model was presented by Solow in the following researches: "A Contribution to the Theory of Economic Growth" (1956) and "Technical Change and the Aggregate Production Function" (1957)

\section{DYNAMIC MACROECONOMIC MODEL OF R.SOLOW}

R. Solow model can be considered both in absolute terms, such as [5]:

$$
\left\{\begin{array}{l}
Y=F(K, L)=I+C, \\
L(t)=L_{0} e^{v \cdot t}, \\
\frac{d K}{d t}=-\mu K+I, K(0)=K_{0}, \\
I=\rho Y, C=(1-\rho) Y,
\end{array},\right.
$$

and in relative terms, per unit of labor resources, assuming that $F(K, L)$ in (1) is a neo-classical homogeneous first-order function:

$$
\left\{\begin{array}{l}
y=f(k)=i+c, \\
\frac{d k}{d t}=\rho y-\lambda k, k(0)=k_{0}=\frac{K_{0}}{L_{0}}, \\
i=\rho y, c=(1-\rho) y .
\end{array}\right.
$$

where $Y=Y(t)$ - gross domestic product (GDP) or gross regional product (GRP); $K=K(t)$ - stock of capital ("Capital"), $L=L(t)$ - human resources, $I=I(t)$ investment; $C=C(t)$ - consumption; $k(t)=\frac{K(t)}{L(t)}$ - capital intensity; $y(t)=\frac{Y(t)}{L(t)}$ - labor productivity; $i(t)=\frac{I(t)}{L(t)}$ - 
Specific investment; $c(t)=\frac{C(t)}{L(t)}-$ per capita consumption; $v \in(-1 ; 1)$ - annual growth rate of employed, $L_{0}=L(0)$, $\mu \in(0 ; 1)$ - rate of retirement, $\rho \in(0 ; 1)$ - rate of accumulation, $\lambda=\mu+v$.

The key point in the Solow model (2) is equality $\frac{d k}{d t}=\rho y-\lambda k$. It follows from this equation that the dynamics of changes in the level of capital intensity of one employee is determined by the ratio of two quantities, namely the investment actually made in the economy $(\rho y)$ and the amount of investment $(\lambda k)$ that is necessary to maintain the reached level of capital intensity $k$ in the conditions of population growth at rate $v$ and the capital replacement at rate $\mu$. If the actual investment is less than what is needed to maintain $(\rho y<\lambda k)$, the level of capital intensity $k$ decreases. The parameter increases if $\rho y>\lambda k$.

The concept of stationary (time-independent) trajectories of the system (2) could be defined as:

$$
\left\{\begin{array}{l}
y=y^{0}=\text { const }, \\
i=i^{0}=\text { const } \\
c=c^{0}=\text { const } .
\end{array}\right.
$$

As one can see from function (2), these conditions will be fulfilled if $\frac{d k}{d t}=0$, or $\rho y-(\mu+v) k=0$, in other words, if capital intensity $k$ is established at certain constant level $k=k^{0}$, which can be found as a solution of the following equation:

$$
\rho(1-a) y-\lambda k=0
$$

or

$$
\rho y=\lambda k \text {. }
$$

Since $f(0)=y(0)=0, f^{\prime}(k)>0, f^{\prime \prime}(k)<0$, then under condition $(\rho y)_{k=0}^{\prime}=\rho y^{\prime}(0)>\lambda$, equation (3) has unique solution $k=k^{0}$ (excluding trivial solution $k=0$ ).

Thus, if $k=k^{0}$, then the values of actual $\rho f(k)$ and necessary (restoring) $\lambda k$ investment coincide. In a steady state, capital intensity ratio $k$ is unchanged; labor productivity $y$ is constant $\left(y=f\left(k^{0}\right)\right)$; the total volume of production $Y$ grows with tempo $v$, as well as the total stock of capital $K$. This is true in the absence of technological progress (with unchanged labor efficiency).

This model shows that population growth has a negative impact on the standard of living, and this is due to the effect of "dilution of capital": at given saving rate $(\rho)$ and the growth rate of population growth $(v)$ (and, accordingly, ratio $\lambda$ ), capital intensity $(k)$ will be stabilized by a lower level, which will result in a decreased productivity of labor $(y)$ [11]. In other words, population change affects the amount of a stable level of capital intensity, but does not affect the growth rates of capital intensity and labor productivity in a stable state.

R. Solow models were built for the regions of the Volga Federal District on the basis of statistical data for 15 years (2000 - 2014) [14]. Therewith three types of factors were considered as labor resources: population $-L_{1}$; the number of economically active population $L_{2}$ - and the number of people employed in the economy - $L_{3}$ [13]. As a result, the following data were obtained:

TABLE I. R. SOlOW MODEL PARAMETERS FOR THE VOLGA FEDERAL DISTRICT.

\begin{tabular}{|c|c|c|c|c|c|c|}
\hline № & Region & $\mu$ & $\rho$ & $v_{1}$ & $v_{2}$ & $v_{3}$ \\
\hline 1 & $\begin{array}{c}\text { Republic of } \\
\text { Bashkortostan }\end{array}$ & 0.0903 & 0.2328 & -0.0008 & 0.0006 & 0.0053 \\
\hline 2 & Kirov region & 0.0439 & 0.2032 & -0.0118 & -0.0141 & -0.0116 \\
\hline 3 & Mari El Republic & 0.0563 & 0.2469 & -0.0053 & -0.0016 & 0.0042 \\
\hline 4 & The Republic of & 0.0613 & 0.3245 & -0.0085 & 0.0014 & 0.0065 \\
\hline 5 & $\begin{array}{c}\text { Nizhny Novgorod } \\
\text { Region }\end{array}$ & 0.0759 & 0.2505 & -0.0069 & -0.0031 & -0.0003 \\
\hline 6 & Orenburg region & 0.0793 & 0.2067 & -0.0068 & -0.0007 & 0.0052 \\
\hline 7 & Penza region & 0.0531 & 0.2541 & -0.0067 & -0.0040 & 0.0014 \\
\hline 8 & Perm Region & 0.0554 & 0.2132 & -0.0060 & -0.0075 & -0.0037 \\
\hline 9 & Samara Region & 0.0657 & 0.2051 & -0.0016 & 0.0024 & 0.0080 \\
\hline 10 & Saratov region & 0.0622 & 0.2152 & -0.0058 & -0.0035 & 0.0143 \\
\hline 11 & Republic of Tatarstan & 0.0792 & 0.2855 & 0.0011 & 0.0065 & 0.0101 \\
\hline 12 & Udmurt republic & 0.0597 & 0.1869 & -0.0034 & 0.0013 & 0.0049 \\
\hline 13 & Ulyanovsk region & 0.0617 & 0.2292 & -0.0082 & -0.0021 & -0.0004 \\
\hline 14 & Chuvash Republic & 0.0657 & 0.2639 & -0.0051 & 0.0009 & 0.0043 \\
\hline 15 & Volga Federal & & & & & \\
& District & 0.0679 & 0.2350 & -0.0044 & -0.0012 & 0.0030 \\
\hline
\end{tabular}

Examining models (1) and (2), it is possible to conclude that with a constant volume of labor resources, the dynamics of the output depends on the amount of capital (in this case, capital intensity). The volume of capital depends on the volume of investment and the retirement of fixed assets. The volume of investment depends on the rate of accumulation, and if the rate of accumulation increases, the investment grows and exceeds the capital outflow, which in turn leads to an increase in the fund-raising ratio, with growth of which the investment growth rate falls. Investment increases the volume of capital, while capital retirement brings it down. And the equilibrium level of the labor-endowment of labor is determined by the level of the capital stock, at which investment is equal to the retirement of capital. At this level, the economic system will be in a stable state, or in a state of dynamic equilibrium [8].

With the growth of labor resources and the unchanged volume of capital, the stock-in-trade is declining. Therefore, investment should cover not only capital replacement, but at the same time provide new workers with capital at the same level. In order to keep capital intensity at the same level in the context of growing population, the capital should grow in accordance with the rate of population growth. 
Thus, from R. Solow model, it follows that the rate of accumulation is the most important factor that determines the stable level of capital intensity and, accordingly, a stable level of labor productivity. Countries with a higher rate of accumulation are characterized by greater specific investment, which, in principle, allows them to have a higher level of capital intensity and a higher rate of economic growth.

\section{CALCUlation OF SOURCES OF ECONOMIC GROWTH. SOLOW RESIDUAL.}

Currently, researchers of regional development pay special attention to the innovative component of the territories, as there is a direct connection between the region's innovation and the pace of its socio-economic development. Innovations play a key role in enhancing the competitiveness of the economy, of a knowledge-based economy. Innovation policy is an integral part of the strategy of industrial-innovative development and is the main tool for increasing the competitiveness of the economy.

The contribution of scientific and technological progress in this model is estimated using the so-called Solow residual, which is defined as the surplus, what remains in output growth after subtracting volume of growth in the factors of production (capital and labor). The next thing to consider is the impact of technical (technological) progress, using the apparatus of production functions of the form:

$$
Y(t)=A(t) \cdot F(K(t), L(t)),
$$

where $A=A(t)$ - a function of time $t$, that characterises the level of technological progress development. Differentiating this function with respect to variable $t$, it's possible to get the following expression:

$$
G_{Y}=G_{A}+E_{Y, K} \cdot G_{K}+E_{Y, L} \cdot G_{L},
$$

which is a production function in the so-called tempo recording form. Here:

$$
\frac{d Y / d t}{Y}=G_{Y} \text { - rate of output growth, the relative increase in }
$$
output during a period of time $t$;

$$
\begin{aligned}
& \frac{d K / d t}{K}=G_{K}-\text { rate of capital growth; } \\
& \frac{d L / d t}{L}=G_{L}-\text { rate of increase in labor; }
\end{aligned}
$$

$$
\frac{d A / d t}{A}=G_{A}-\text { rate of technical progress, or the rate of }
$$
growth of output due to scientific and technological progress;

$$
\begin{aligned}
& \frac{\partial F}{\partial K} \cdot \frac{K}{F}=E_{Y, K} \text { - elasticity of output for capital expenditures; } \\
& \frac{\partial F}{\partial L} \cdot \frac{L}{F}=E_{Y, L} \text { - elasticity of output for labor costs. }
\end{aligned}
$$

The last equality allows one to determine to what extent the increase in output is due to a change in the number of resources used $\left(E_{Y, K} \cdot G_{K}+E_{Y, L} \cdot G_{L}\right)$, and to define -the role of technological progress $\left(G_{A}\right)$.

For example, for the production function of form $Y(t)=e^{\gamma t} F(K(t), L(t))=\alpha_{0} e^{\gamma t} K(t)^{\alpha_{1}} L(t)^{\alpha_{2}} \quad$ can $\quad$ be obtained:

$$
G_{Y}=\gamma+\alpha_{1} \cdot G_{K}+\alpha_{2} \cdot G_{L},
$$

and for function $Y(t)=\alpha_{0} e^{\gamma t} K(t)^{\alpha} L(t)^{1-\alpha}-$

$$
G_{Y}=\gamma+\alpha \cdot G_{K}+(1-\alpha) \cdot G_{L} \text {. }
$$

It should be noted that the last equation implies that free term $\gamma$ represents the rate of neutral (autonomous) technical progress, not directly related to the increase in the expenditure of labor and capital, but reflects the intensification of production at the macro level [12]. An example of calculating parameter $\gamma$ for the regions of the Volga Federal District is given in the following table.

TABLE II. ASSESSMENT OF THE LEVEL OF SCIENTIFIC AND TECHNOLOGICAL PROGRESS USING THE COBB-DOUGLAS PRODUCTION FUNCTION AT COMPARABLE PRICES.

\begin{tabular}{|c|c|c|c|c|}
\hline № & Region & $L_{1}$ & $L_{2}$ & $L_{3}$ \\
\hline 1 & $\begin{array}{c}\text { Republic of } \\
\text { Bashkortostan }\end{array}$ & 0.0503 & 0.0557 & 0.0577 \\
\hline 2 & Kirov region & 0.0676 & 0.0815 & 0.0778 \\
\hline 3 & Mari El Republic & 0.0456 & 0.0498 & 0.0484 \\
\hline 4 & The Republic of & 0.0455 & 0.0455 & 0.0461 \\
\hline 5 & Nizhny Novgorod Region & 0.0473 & 0.0460 & 0.0483 \\
\hline 6 & Orenburg region & 0.1512 & 0.1225 & 0.1181 \\
\hline 7 & Penza region & 0.0965 & 0.0782 & 0.0741 \\
\hline 8 & Perm Region & 0.0153 & 0.0227 & 0.0243 \\
\hline 9 & Samara Region & 0.0489 & 0.0526 & 0.0517 \\
\hline 10 & Saratov region & 0.0630 & 0.0611 & 0.0374 \\
\hline 11 & Republic of Tatarstan & 0.0520 & 0.0485 & 0.0467 \\
\hline 12 & Udmurt republic & 0.0274 & 0.0395 & 0.0376 \\
\hline 13 & Ulyanovsk region & 0.0618 & 0.0547 & 0.0536 \\
\hline 14 & Chuvash Republic & 0.0041 & 0.0473 & 0.0439 \\
\hline 15 & Volga Federal District & 0.0420 & 0.0570 & 0.0512 \\
\hline
\end{tabular}

In addition, when performing practical calculations, it should be borne in mind that parameter $\gamma$ is built on the residual principle. In other words, it reflects the influence on the growth rate of output of all other factors, except labor and capital. This means that this parameter characterizes the impact on release and some other factors. However, for most microeconomic processes, the main role among "other factors" belongs precisely to technical progress.

To assess the contribution of production factors to economic growth, R. Solow proposed using the production function with constant returns to the scale of the species: $Y=A \cdot F(K, L)$, where $A$ reflects the level of development of scientific and technological progress (technology) and is often interpreted as a change or increase in the aggregate productivity of production factors. 
According to the formula of the total differential, the change in output volume $\Delta Y$ can be approximately calculated as follows $(\Delta Y \approx d Y)$ :

$\Delta Y=\frac{\partial Y}{\partial K} \cdot \Delta K+\frac{\partial Y}{\partial L} \cdot \Delta L+\frac{\partial Y}{\partial A} \cdot \Delta A=\frac{\partial Y}{\partial K} \cdot \Delta K+\frac{\partial Y}{\partial L} \cdot \Delta L+F(K, L) \cdot \Delta A=$ $=M P K \cdot \Delta K+M P L \cdot \Delta L+F(K, L) \cdot \Delta A$,

where $\Delta K, \Delta L$ and $\Delta A$ - changes in the values of factors of production; $\quad M P K=\frac{\partial Y}{\partial K}, \quad M P L=\frac{\partial Y}{\partial L}-$ the marginal productivity of capital and labor, respectively. This equation can be transformed to the form:

$$
\frac{\Delta Y}{Y}=\left(K \cdot \frac{M P K}{Y}\right) \cdot \frac{\Delta K}{K}+\left(L \cdot \frac{M P L}{Y}\right) \cdot \frac{\Delta L}{L}+\frac{\Delta A}{A},
$$

where the expressions in parentheses are capital and labor elasticity of the output.

Equality (4) means that the growth rate of output $\frac{\Delta Y}{Y}$ is represented as the sum of three terms:

1) The growth rate of capital $\frac{\Delta K}{K}$, multiplied by the share of capital in total income.

2) The growth rate of labor $\frac{\Delta L}{L}$, multiplied by the share of labor in total income.

3) The growth rate of aggregate productivity of factors of production $\frac{\Delta A}{A}$.

Relations $M P K \cdot \frac{K}{Y}$ and $M P L \cdot \frac{L}{Y}$ can be considered as a share of income for capital and labor, if it is assumed that, in the conditions of perfect competition, labor and capital are paid in accordance with their marginal productivity.

Based on statistical data, it is possible to calculate the contribution of labor and capital to economic growth. The evaluation of the contribution to the economic growth of scientific and technological progress can not be carried out directly, therefore it is usually calculated as the remainder term of equation (4) and is called the Solow residual:

$$
\frac{\Delta A}{A}=\frac{\Delta Y}{Y}-\frac{\partial Y}{\partial K} \cdot \frac{K}{Y} \cdot \frac{\Delta K}{K}-\frac{\partial Y}{\partial L} \cdot \frac{L}{Y} \cdot \frac{\partial L}{L} .
$$

Therefore, Solow residual $\frac{\Delta A}{A}$, strictly speaking, determines not only the contribution of scientific and technological progress to economic growth, but the share of economic growth that can not be directly measured by the direct measurements and can be explained by any reasons, except for changes in the volumes of labor and capital employed.

If we use a Cobb-Douglas PF $Y=A K^{\alpha} L^{1-\alpha}$, then relation (5) takes the form:

$$
\frac{\Delta Y}{Y}=\alpha \frac{\Delta K}{K}+(1-\alpha) \frac{\Delta L}{L}+\frac{\Delta A}{A},
$$

and the Solow residual will be calculated by the formula:

$$
\frac{\Delta A}{A}=\frac{\Delta Y}{Y}-\alpha \frac{\Delta K}{K}-(1-\alpha) \frac{\Delta L}{L} .
$$

On the other hand, if as a PF, is taken a multiplicative PF of a form $Y=A K^{\alpha_{1}} L^{\alpha_{2}}$, then the Solow residual will be calculated as:

$$
\frac{\Delta A}{A}=\frac{\Delta Y}{Y}-\alpha_{1} \frac{\Delta K}{K}-\alpha_{2} \frac{\Delta L}{L} .
$$

If denote the share of capital in total income as $\theta$, and the share of labor as $(1-\theta)$, then from (4), follows:

$$
\frac{\Delta Y}{Y}=\theta \frac{\Delta K}{K}+(1-\theta) \frac{\Delta L}{L}+\frac{\Delta A}{A} .
$$

The choice of a specific formula for the production function allows us to estimate the values of parameters $\theta$ and $\gamma=\frac{\Delta A}{A}$. For example, if a statistically significant CobbDouglas PF is constructed for a macroeconomic system, then it can be approximately assumed that $\theta=\alpha$ (see (6)), that is, it is possible to use parameters $\alpha$ and $1-\alpha$ for estimating the shares of capital and labor in aggregate income. And conversely, if fractions $\theta$ and $1-\theta$ are known and, then they can be used as approximate values of parameters $\alpha$ and $1-\alpha$ for the Cobb-Douglas production function. If values $\alpha$ and $1-\alpha$ are known, then the only parameter that remains unknown is the rate of technical progress $\gamma$, and it can be estimated by statistical methods.

An example of calculation of the Solow residual for the regions of the Volga Federal District is given in the following table.

TABLE III. CALCULATION OF SOLOW RESIDUAL BY FORMULA $\frac{\Delta A}{A}=\frac{\Delta Y}{Y}-\alpha \frac{\Delta K}{K}-(1-\alpha) \frac{\Delta L}{L}$ IN A COMPARABLE PRICES.

\begin{tabular}{|c|c|c|c|c|}
\hline № & Region & $L_{1}$ & $L_{2}$ & $L_{3}$ \\
\hline 1 & $\begin{array}{c}\text { Republic of } \\
\text { Bashkortostan }\end{array}$ & 0.0571 & 0.0555 & 0.0523 \\
\hline 2 & Kirov region & 0.0472 & 0.0491 & 0.0473 \\
\hline 3 & Mari El Republic & 0.0636 & 0.0612 & 0.0609 \\
\hline 4 & The Republic of & 0.1686 & 0.1684 & 0.0500 \\
\hline 5 & Nizhny Novgorod Region & 0.0518 & 0.0458 & 0.0449 \\
\hline 6 & Orenburg region & 0.1013 & 0.0871 & 0.0864 \\
\hline 7 & Penza region & 0.0409 & 0.0382 & 0.0383 \\
\hline 8 & Perm Region & 0.0373 & 0.0383 & 0.0392 \\
\hline 9 & Samara Region & 0.0465 & 0.0452 & 0.0424 \\
\hline 10 & Saratov region & 0.0638 & 0.0566 & 0.0539 \\
\hline 11 & Republic of Tatarstan & 0.0415 & 0.0388 & 0.0380 \\
\hline 12 & Udmurt republic & 0.0278 & 0.0282 & 0.0341 \\
\hline 13 & Ulyanovsk region & 0.0479 & 0.0433 & 0.0442 \\
\hline 14 & Chuvash Republic & 0.0663 & 0.1722 & 0.0606 \\
\hline 15 & Volga Federal District & 0.0458 & 0.0454 & 0.0429 \\
\hline
\end{tabular}


Sufficient similarity of values $\gamma$ and estimates of Solow residual $\frac{\Delta A}{A}$, obtained during modeling, confirmed the expediency of using multiplicative production functions to assess the influence of scientific and technical progress, for example, in the dynamics of GRP of the Volga Federal District.

The use of the Cobb-Douglas PF is one of the possible ways to evaluate and to analyze these shares. However, these estimates for the Cobb-Douglas PF are not always stable, and at some time periods, statistically significant estimates are not obtained at all.

The Cobb-Douglas function can also be evaluated in the case of a centrally planned economy, however, in this case, elasticity coefficients $\alpha$ and $1-\alpha$ may deviate from the shares of capital and labor $\theta$ and $1-\theta$ in the output. Such deviation will indicate the inefficient nature of the distribution of production resources and the need for their redistribution.

\section{DYNAMIC SOLOW MODEL WITH DELAY WHEN ENTERING FUNDS}

In Solow models (1) and (2), constructed above, it was assumed that the investment turns into funds instantly. But in real economic practice, investment development takes place in the context of time, that is, with the delay. Assuming that investment $I(\tau)$ made at some point in time $\tau$ will be gradually developed over a period of time $t>\tau$, according to the exponential probability distribution law, then at any point in time $t$, the investment made will amount to:

$$
Q(t)=\int_{0}^{t} \theta \cdot e^{-\theta(t-\tau)} I(\tau) d \tau, \theta>0 .
$$

Then R. Solow model (1), with the delay in the introduction of funds, can take the form:

$$
\left\{\begin{array}{l}
Y=F(K, L)=I+C, \\
L=L_{0} e^{v t}, \\
\frac{d K}{d t}=-\mu K+Q, K(0)=K_{0}, \\
\frac{d Q}{d t}=\theta \cdot I-\theta \cdot Q, C=(1-\rho) Y .
\end{array}\right.
$$

If $F(K, L)$ is a first-order neoclassical homogeneous function (with a constant return to scale), then system (7) can be also represented in relative terms:

$$
\left\{\begin{array}{l}
y=f(k)=i+c, \\
\frac{d k}{d t}=-\lambda k+q, \lambda=\mu+v, k(0)=k_{0}, \\
\frac{d q}{d t}=-\theta_{0} q+\theta \rho f(k), \theta_{0}=v+\theta, \\
c=(1-\rho) f(k) .
\end{array}\right.
$$

where $q(t)=\frac{Q(t)}{L(t)}$.

The R. Solow model can be used to construct forecasts of the gross regional product [7]. Let us give an example of the construction of such forecast (in prices of 2014, billion rubles) for the Volga Federal District using statistically and economically significant production functions.

TABLE IV. FORECASTING THE GROSS REGIONAL PRODUCT OF THE VOLGA FEDERAL DISTRICT.

\begin{tabular}{|c|c|c|}
\hline Year & $\begin{array}{c}\text { Solow model without } \\
\text { delay in the input of } \\
\text { funds }\end{array}$ & $\begin{array}{c}\text { Solow model with } \\
\text { delay in input of } \\
\text { funds }\end{array}$ \\
\hline 2015 & 9649.5 & 9461.2 \\
\hline 2016 & 10249.3 & 9881.1 \\
\hline 2017 & 10894.0 & 10696.9 \\
\hline
\end{tabular}

Naturally, using models (7) - (8), the results of the forecast were less than for models (1) - (2).

\section{Optimal Control Problem In the Solow Model}

The next thing that will be considered is the Solow model (2) assuming that the rate of accumulation $\rho$ is not a constant. That is, in model (2), investment $i=\rho \cdot f(k)$ can be replaced with:

$$
\rho f(k)=f(k)-c(t)
$$

Then the so-called basic equation of the controlled system will be obtained in the form:

$$
\frac{d k}{d t}=-\lambda k+f(k)-c(t), k(0)=k_{0} .
$$

As a controlling parameter, consumption function $c(t)$, which for all $t \geq 0$ is piecewise continuous and satisfies the condition:

$$
0<c_{1} \leq c(t) \leq f(k(t))
$$

where $c_{1}$ - the lower maximum permissible limit of specific consumption.

The task of managing the system is to maximize the current (discounted) utility from consumption [6]:

$$
\int_{0}^{\infty} e^{-\delta \cdot t} u(c(t)) d t \rightarrow \max ,
$$

where $\delta$ - growth force (discounting parameter); $u(c)$ utility function of consumption with properties: $u(c)>0$, $u^{\prime}(c)>0, u^{\prime \prime}(c)<0, \lim _{c \rightarrow+0} u^{\prime}(c)=\infty, \lim _{c \rightarrow \infty} u^{\prime}(c)=0$.

Thus, there is the following problem of optimal consumption utility management, in which there is single 
phase variable $k(t)$ and single control parameter (function) $c(t)$ :

$$
\left\{\begin{array}{l}
\max _{c(t)} \int_{0}^{\infty} e^{-\delta \cdot t} u(c(t)) d t, \\
\frac{d k}{d t}=-\lambda k+f(k)-c, k(0)=k_{0}, \\
0<c_{1} \leq c(t) \leq f(k) .
\end{array}\right.
$$

The right end of trajectory $k(t)$ (for $t \rightarrow \infty$ ) is not fixed, but it satisfies condition $\lim _{t \rightarrow+\infty} k(t) \geq 0$. The solution of this problem, using the Pontryagin maximum principle [9], will be trajectory $\left(k^{*}(t) ; c^{*}(t)\right)$ for which the utility of consumption is maximal.

\section{CONCLUSION}

The growth of labor resources can be considered as one of the reasons for continuous economic growth in the conditions of a stable state of the economy. And technological progress is perhaps the only condition for continuous improvement in the standard of living of population, because it is possible to see a steady increase in the capital intensity when technological progress is present. The R. Solow model separates scientific and technical progress as the only basis for sustainable growth of well-being and allows one to find the optimal growth option, called the "golden rule of accumulation", which provides the maximum consumption per capita.

Naturally, R. Solow model is not free from certain shortcomings. It analyzes the states of stable equilibrium that are achieved in the long term, that is, it describes the mechanisms of long-term economic growth, maintaining equilibrium in the economic system and full employment of production factors. But for economic policy, issues related to the short-term dynamics of the level of production and the level of the well-being of the population are also important. The model does not consider a number of growth restrictions of growth that are significant in modern conditions, for example, environmental, resource, etc. [3]. The model uses the
Cobb-Douglas production function, which describes a certain type of interaction of production factors that does not always reflect the state of the real situation in the economy $[2,15]$. Modern theories of economic growth [1] try to overcome these flaws.

\section{References}

[1] R.J. Barro, H. Sala-i-Martin, Economic growth, BINOM. Laboratory of Knowledge, 2015, 824 p.

[2] O.O. Zamkov, A.V. Toltopyenko, Yu.N. Cheremnykh, Mathematical methods in economics, MSU, DIS, 1997, 368 p.

[3] D.Yu. Katalevsky, Fundamentals of simulation and system analysis in management: a textbook, Izd. House "Case" RANHiGS, 2015, 496 p.

[4] T. N. Kokotkina, N. S. Sadovin, D.E. Bespalov, V.A. Borisov, E.I Tsaregorodtsev, A.A. Malinina, E.O. Vasilyeva, "A Dynamic Model of Regional Economic Growth," Mediterranean Journal of Social Sciences, Vol 6, No 3, S7, pp. 139-148, 2015.

[5] V.A. Kolemaev, Mathematical Economics: A Textbook for Universities ,UNITY, 1998, 240 p.

[6] B.A. Lagosha, T.G. Apalkov, Optimal management in the economy theory and applications: a tutorial, Finance and Statistics, 2008, 224 p.

[7] Jeffrey H. Moore, Larry R. Waderford, Economic modeling in Microsoft Excel, Publishing house "Williams", 2004, 1024 p.

[8] R.M. Nureev, Economics of development: models of the formation of a market economy: Textbook, INFRA-M, 2001, 240 p.

[9] L.S. Pontryagin, V.G. Boltyansky, RV Gamkrelidze, E.F. Mishchenko, Mathematical theory of optimal processes, Nauka, 1983, $392 \mathrm{p}$

[10] D. Romer, Higher Macroeconomics: textbook, Izd. House of the Higher School of Economics, 2014, 855 p.

[11] A.A. Sagradov, Economic demography: Textbook, Prospekt, 2016, 253 $\mathrm{p}$

[12] N.S. Sadovin, T.N. Kokotkina, T.G. Barkalova, E.I. Tsaregorodsev, "Modeling of the Gross Regional Product on the Basis of Production Functions," International journal of environmental \& science education, VOL. 11, NO. 17, pp.10635-10650, October 2016

[13] L.A. Soshnikova, V.N. Tamashevich, G. Uebe, M. Shefer Multidimensional Statistical Analysis in Economics: Textbook, UNITY-DANA, 1999, 598 p.

[14] Federal Service of State Statistics [Electronic resource]. - Access mode: http://www.gks.ru, free.

[15] S.I. Shelobayev, Economic-mathematical methods and models: Proc. Manual for universities, UNITY-DANA, 2005, 287 p. 